\title{
EXTRAÇÃO DE SEMENTES DE RODOVIAS A PARTIR DE IMAGENS AÉREAS DIGITAIS
}

Ely França dos Santos Ferreira ${ }^{1}$, Francisco Assis da Silva ${ }^{2}$, Mário Augusto Pazoti ${ }^{2}$, Leandro Luiz de Almeida ${ }^{2}$, Robson Augusto Siscoutto ${ }^{2}$

${ }^{1}$ Discente da Faculdade de Informática da UNOESTE. ${ }^{2}$ Docente da Faculdade de Informática da UNOESTE

\section{RESUMO}

Este artigo apresenta uma metodologia para extração de sementes (segmentos) de rodovia a partir de imagens aéreas digitais, essas imagens geralmente possuem variações, o que envolve uma análise complexa e caracteriza um problema desafiador nessa área. A implementação do trabalho consistiu na aplicação técnicas para a detecção de possíveis sementes de rodovias. Este trabalho apresenta uma metodologia na eliminação de pontos inválidos da rodovia utilizando a aplicação do Algoritmo de Canny Modificado. Na segmentação dos pontos válidos para construção de sementes, foi aplicado o algoritmo de Douglas-Peucker. Na extração das rodovias, foram encontrados problemas em relação aos pontos válidos e inválidos das sementes e imagens que possuem estradas rurais. Foram realizados experimentos com imagens aéreas de rodovias para comprovar a metodologia proposta.

Palavras-chave: extração de rodovias; sementes de rodovias; visão computacional; cartografia.

\section{EXTRACTION OF SEED ROAD FROM DIGITAL AERIAL IMAGES}

\begin{abstract}
This paper presents a methodology for extracting road seeds (segments) from digital aerial images, these images often have variations, which involves complex analysis and characterizes a challenging problem in this area. This work consists in implementing techniques for detecting possible road seed. This paper presents a methodology in eliminating invalid points of the roads using the application of Modified Canny Algorithm. In the segmentation of valid points for seed construction was applied the Douglas-Peucker algorithm. In the road extraction, problems were found in relation to valid and invalid seed and in images that have rural roads. Experiments were performed with aerial images of roads to prove the proposed methodology.
\end{abstract}

Keywords: road extraction, seed road, computer vision, cartography. 


\section{INTRODUÇÃO}

A malha viária é a superfície por onde transitam veículos, pessoas e animais compreendendo as rodovias, assim denominadas quando localizadas fora das áreas urbanas, e as vias denominadas ruas e avenidas quando localizadas no interior das áreas urbanas (BRASIL, 1997). A malha viária é de fundamental importância para o desenvolvimento econômico de qualquer país, uma vez que representam a solução para conexão entre regiões habitadas e o meio de transporte convencional de bens e pessoas.

Nos últimos anos, as tecnologias em Sensoriamento Remoto $^{1}$ e Fotogrametria Digital $^{2}$ tiveram um avanço significativo, assim, a extração de formas cartográficas em imagens aéreas demonstra ser de grande interesse na comunidade científica. Este processo de extração é de extrema importância na captura de dados e atualização de bases cartográficas. Essas bases são importantes para as atualizações de Sistemas de Informações Geográficas (SIGs), voltados ao monitoramento ambiental, ao planejamento urbano e ao gerenciamento de tráfego (ISHIBASHI, 2008).

\footnotetext{
${ }^{1}$ Sensoriamento Remoto: representa a aquisição de informações sem contato físico com os objetos, as fotografias aéreas são frutos do sensoriamento remoto (PONZONI; NOVO, 2001).

2 Fotogrametria Digital: são medições executadas através de fotografias, é a ciência e tecnologia de se obter informação confiável por meio de imagens adquiridas por sensores (COELHO; BRITO, 2007).
}

A extração de rodovias em imagens teve início na década de 70, com trabalhos pioneiros como o de Bajcsy e Tavakoli (1976), em que foi desenvolvido um algoritmo de reconhecimento de estradas, sendo a detecção realizada pela verificação dos valores cinza dos pixels. Na década de 80, Fischler, Tenenbaum e Wolf (1981) descreve uma abordagem para detectar e delinear rodovias. Nesse trabalho, o autor estabelece uma região de análise de forma manual e identifica os pontos sementes, e o contorno da rodovia é gerado aplicando-se um algoritmo de programação dinâmica.

Dal Poz e Agouris (2001) abordam um método de extração semiautomática de rodovias em imagens aéreas digitais, sendo que no processo de extração, alguns pontos sementes devem ser fornecidos pelo operador. Este procedimento dá origem a um polígono inicial, a ser refinado através de uma estratégia iterativa. Em cada iteração, novos vértices aproximados são adicionados, através de uma interpolação linear (linha que se ajusta a dois pontos), entre os pares de vértices preexistentes. $O$ processo termina quando os novos vértices inseridos não contribuem mais com o refinamento do polígono descrevendo a rodovia.

Trabalhos recentes como o de Zanin, Ishibashi e Dal Poz (2007), propõe uma ferramenta amplamente utilizada na área de 
Visão Computacional, onde ocorre a extração semiautomática de rodovias sobre uma Imagem Híbrida ${ }^{3}$. O trabalho visa criar um modelo baseado no esqueleto das rodovias, modelo este que vai auxiliar na extração dos cruzamentos de rodovias. Ishibashi, Dal Poz (2009) apresentada uma metodologia para a extração automática de segmentos de rodovia em imagens de diferentes resoluções (baixa, média e alta resolução). O método consiste na análise do histograma da imagem, onde é feita a detecção de linhas com seleção de escala automática, a aplicação de limiarização por comprimento visando eliminar quase que totalmente os ruídos provocados na detecção de linhas, e por fim, é aplicado um algoritmo de poligonação, para reduzir significativamente o número de pontos de linhas previamente detectadas.

Nos últimos anos a produção cartográfica tem sido pouco eficiente, devido a alguns fatores como a dificuldade de automação e a alta complexidade das cenas envolvidas (imagens aéreas). Os órgãos responsáveis no Brasil não contêm recursos humanos suficientes e subsídios para a aquisição de equipamentos (sensores de alta resolução para imageamento e extração de dados, como câmara CCD e sistemas de

\footnotetext{
${ }^{3}$ Imagem Híbrida: é uma imagem que é percebida de duas maneiras diferentes, referem-se a qualquer imagem montada a partir de componentes diferentes (GENDLER, 2005).
}

varredura laser). A desatualização do país é uma realidade onde pouco desenvolvimento estratégico ocorreu nos últimos anos (ALVES, 2007; SANTOS, 2010), assim o desenvolvimento de trabalhos com imagens aéreas de alta resolução são de grande importância, pois o custo do processo de extração de rodovias na área de cartografia é significativamente alto.

Nesse contexto, este trabalho propõe uma metodologia para extração de sementes de rodovia em imagens aéreas, onde visa desenvolver um método de reconhecimento de rodovias inicialmente baseado no algoritmo de Canny Modificado desenvolvido por Dal Poz e Silva (2002), e a partir desta aplicação cria-se uma imagem de reamostragem, a construção da imagem Base, a detecção de linhas através do Canny Modificado, o armazenamento das linhas detectadas, a eliminação dos pontos inválidos, a aplicação do algoritmo de BSpline, a aplicação do Algoritmo de DouglasPeucker e a construção das sementes de rodovias. Algumas dificuldades foram encontradas devido as imagens possuir variações de iluminação, ruídos, sombras de vegetações e outras que afetam diretamente a análise.

$\mathrm{O}$ artigo esta organizado em seções. A Seção 2 apresenta a fundamentação da metodologia aplicada; na Seção 3 são 
EXTRAÇÃO DE SEMENTES DE RODOVIAS

demonstrados os experimentos e

dificuldades nos reconhecimentos e na construção das sementes; e por ultimo, na Seção 4 é apresentada a conclusão do trabalho e possíveis trabalhos futuros.
2. METODOLOGIA APLICADA PARA EXTRAÇÃO DE SEMENTES DE RODOVIAS

As etapas da metodologia para extração de sementes de rodovias no contexto deste trabalho são mostradas no fluxograma apresentado na Figura 1.

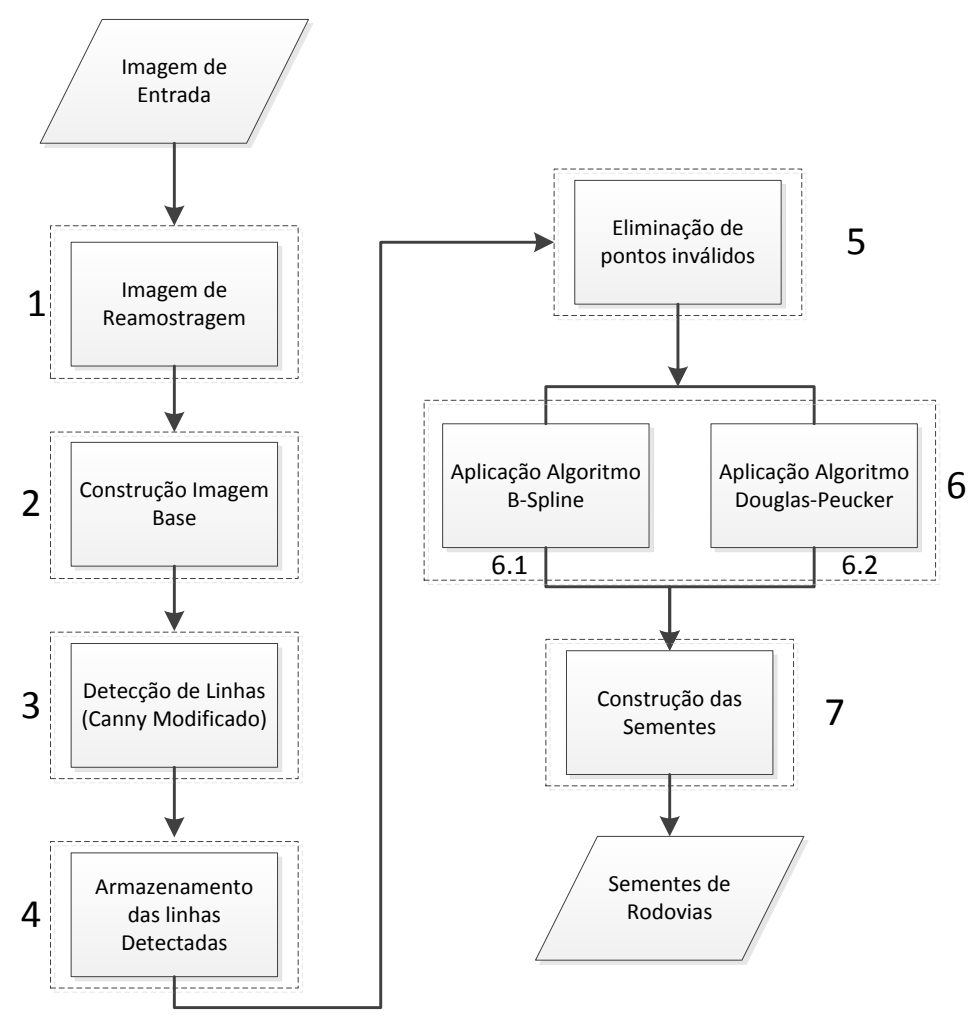

Figura 1. Fluxograma das etapas de extração de sementes de rodovias.

Conforme mostra a Figura 1, a metodologia é dividida em sete etapas para detecção e extração de sementes de rodovias que são detalhadas a seguir.

Imagem de Reamostragem (etapa 1): Uma imagem digital pode ser reamostrada visando reduzir ou aumentar sua resolução espacial, no caso de redução tem-se uma subamostragem e no caso de aumento de resolução tem-se uma interpolação. A reamostragem de imagens é amplamente utilizada em processamento de imagens e vídeos.

Ela é utilizada para ampliar, reduzir e rotacionar imagens. A reamostragem elimina informação irrelevante e indesejável presente na imagem. A detecção das linhas (rodovias) na imagem reamostrada, permite identificar as linhas extraídas da imagem que 
contêm poucas possibilidades de estarem relacionadas com as rodovias, reduzindo drasticamente as linhas irrelevantes na extração de segmentos de rodovia (DAL POZ; VALE, 2004).

\section{Construção da Imagem Base (etapa}

2): Esta Imagem Base é criada a partir da Imagem de Entrada, aplicando-se o método de detecção de bordas Canny (1986). A finalidade de detecção de borda, em geral, é a de reduzir significativamente a quantidade de dados em uma imagem, enquanto preserva as propriedades estruturais a serem utilizadas para o processamento de imagem.

A Figura 2 ilustra um exemplo de aplicação do método de bordas Canny.

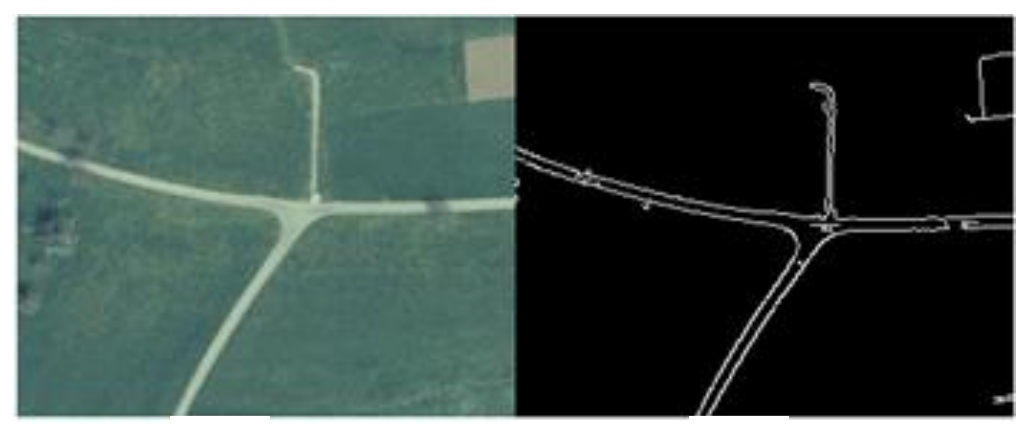

(a)

(b)

Figura 2. (a) Imagem de Entrada e (b) Imagem Base, contendo o resultado da aplicação do algoritmo Canny.

\section{Detecção de Linhas usando o Canny} Modificado (etapa 3): Dal Poz e Silva (2002) propôs um detector de linhas baseado no detector de bordas de Canny (1986). Este detector consiste da manipulação dos níveis de brilho da imagem, apoiado na semelhança das linhas com a primeira derivada das bordas. O detector de linhas, segundo 0 autor, nada mais é do que o detector de Canny (1986) sem a etapa de diferenciação da imagem. A diferenciação é a captura das variações dos níveis de cinza na imagem.

A Figura 3 ilustra um resultado gerado pelo detector de linhas do Canny Modificado, aplicado a uma imagem, onde se pode notar que as rodovias principais foram detectadas como linhas e não como duas bordas contíguas aproximadamente paralelas observado na Figura 2. 


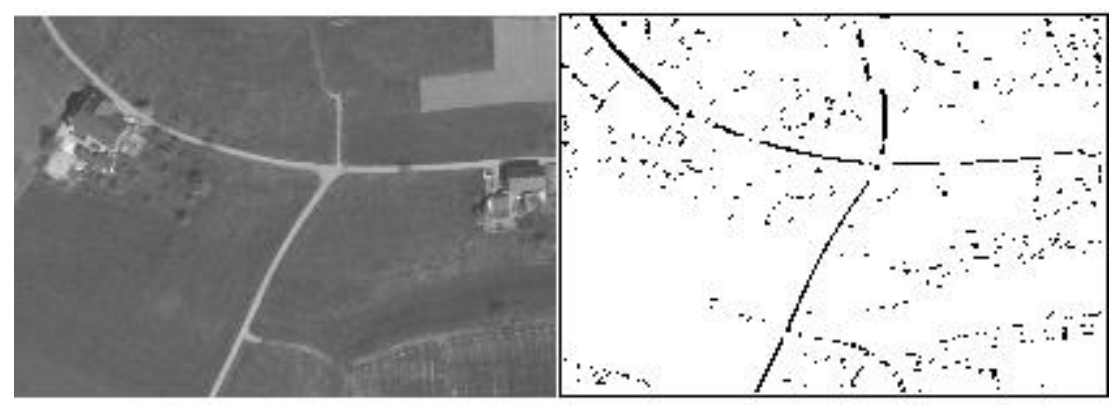

Figura 3. Aplicação do Canny Modificado.

Armazenamento de Linhas uma estrutura de dados, onde cada cadeia de detectadas pelo Canny modificado (etapa 4): pixels contíguos foi armazenada como uma As informações geradas pelo Canny estrutura distinta, representando segmentos modificado (DAL POZ; SILVA, 2002) contêm coordenadas dos pixels necessários para processamentos subsequentes. Foi desenvolvido um método com o intuito de armazenar as informações de cada pixel em da imagem. Estes segmentos são analisados e podem originar possíveis sementes de rodovias. A Figura 4 mostra um exemplo de segmentos encontrados na aplicação do Canny Modificado.

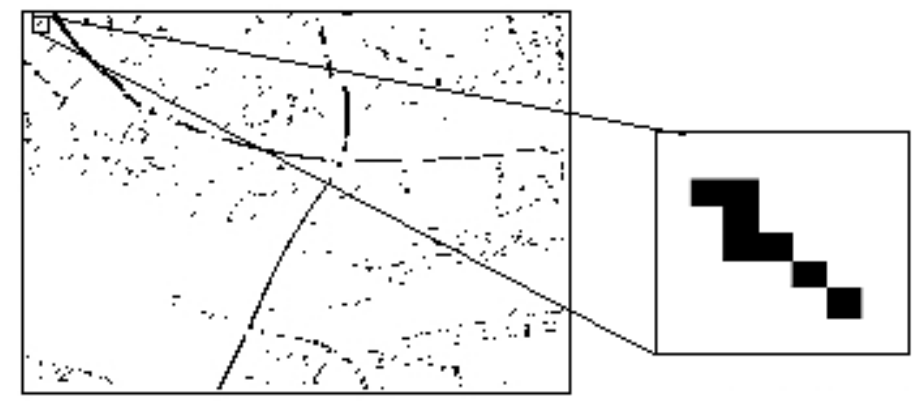

Figura 4. Exemplo de segmentos encontrados na aplicação do Canny Modificado.

A Figura 5 representa o segmento observado na Figura 4 em destaque. Nessa imagem, cada pixel é representado por um quadrículo preto, contendo linha e coluna respectivamente que o descreve: $\{(11,11)$; $(11,12) ; \quad(12,12) ; \quad(13,12) ; \quad(13,13) ; \quad(14,14)$; $(15,15)\}$.

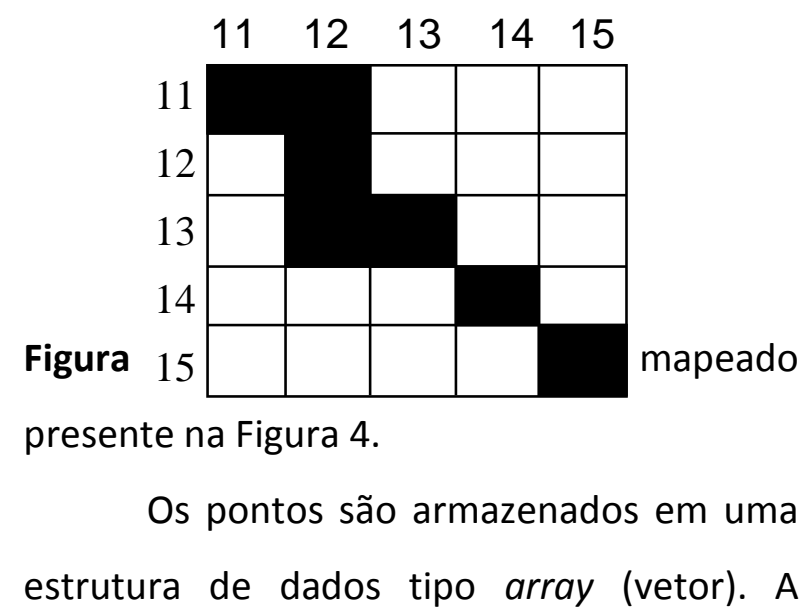


Figura 6 representa o armazenamento dos pontos do segmento representado na Figura 5.

\begin{tabular}{|c|c|}
\multicolumn{1}{c}{$X$} & $Y$ \\
\hline 11 & 11 \\
\hline 11 & 12 \\
\hline 12 & 12 \\
\hline 13 & 12 \\
\hline 13 & 13 \\
\hline 14 & 14 \\
\hline 15 & 15 \\
\hline
\end{tabular}

Figura 6. Armazenamento dos pontos do segmento.

\section{Eliminação de pontos Inválidos}

(etapa 5): Com a aplicação do Canny modificado (Figura 3), vários pontos que não fazem parte do objeto de interesse (as rodovias) são gerados. Esta etapa analisa se cada ponto faz parte de uma semente de rodovia. Os pontos inválidos são descartados.

Para cada ponto são encontrados outros dois pontos através da simplificação do fator de inclinação, os novos pontos geram duas retas podendo determinar a validação do ponto Original.

$\mathrm{Na}$ construção das retas são dados dois pontos $\mathrm{P}_{1}(x, y)$ e $\mathrm{P}_{2}(x, y)$, deste modo pode-se calcular as retas para cada ponto, a reta assumirá $90 \circ$ ou $180^{\circ}$ graus. A inclinação será reconhecida através dos cálculos de $\Delta_{x} \mathrm{e}$
$\Delta_{y}$ respectivamente. O tamanho da reta $(\mathrm{P})$ é determinado analisando a imagem.

Considerando dois pontos $\mathrm{P}_{1}=\left(x_{1}, y_{1}\right)$ e $\mathrm{P}_{2}=\left(x_{2}, y_{2}\right)$ tem-se, $\Delta_{x}=\left|x_{2}-x_{1}\right|$ e $\Delta_{y}=\mid y_{2}$ $-y_{1} \mid$, a construção da reta segue a seguinte lógica:

Para $\Delta_{x}=0$ ou $\Delta_{y}>\Delta_{x}$, a reta é construída com o ângulo de 180응 (percorrendo apenas o eixo " $x$ "). Através do ponto $P_{1}$ são gerados os pontos $P_{1}^{\prime}$ e $P_{1}{ }^{\prime \prime}$ conforme demonstrado a seguir:

$$
\begin{array}{ll}
P_{1}{ }^{\prime} \cdot x=P_{1} \cdot x+P & P_{1}{ }^{\prime \prime} x=P_{1} \cdot x-P \\
P_{1}{ }^{\prime} \cdot y=P_{1} \cdot y & P_{1}{ }^{\prime \prime} y=P_{1} \cdot y
\end{array}
$$

Para $\Delta_{y}=0$ ou $\Delta_{x}>\Delta_{y}$, a reta é construída com o ângulo de 90 (percorrendo apenas o eixo " $y$ "), através do ponto $P_{1}$ são gerados os pontos $\mathrm{P}_{1}^{\prime}$ e $\mathrm{P}_{1}^{\prime \prime}$ conforme demonstrado abaixo:

$$
\begin{array}{ll}
P_{1}^{\prime} \cdot x=P_{1} \cdot x & P_{1}{ }^{\prime \prime} \cdot x=P_{1} \cdot x \\
P_{1}^{\prime} \cdot y=P_{1} \cdot y+P & P_{1}^{\prime \prime} \cdot y=P_{1} \cdot y-P
\end{array}
$$

Um ponto é válido se nos dois seguimentos de cada ponto, quando são percorridos, encontra-se um pixel branco (Borda). A Figura 7 demonstra dois pontos onde $P_{1}$ é um ponto válido e $P_{2}$ é um ponto inválido. Percorrendo do ponto $\mathrm{P}_{1}$ em direção aos pontos $\mathrm{P}_{1}^{\prime}$ e $\mathrm{P}_{1}^{\prime \prime}$ encontra-se bordas nos dois caminhos, entretanto, não ocorre para o ponto $\mathrm{P}_{2}$. 


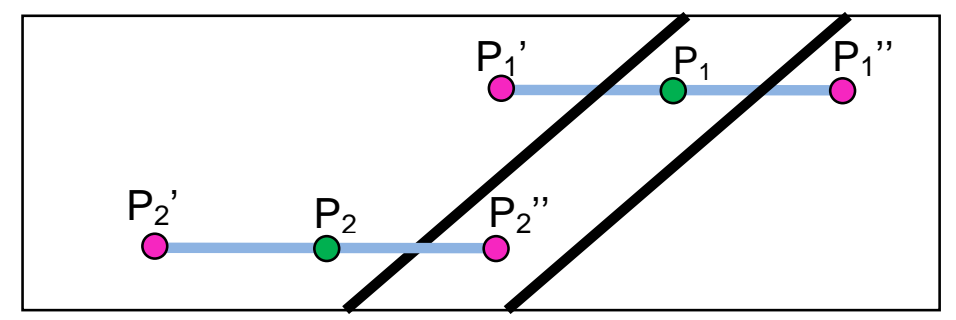

Figura 7. Demonstração de um ponto válido e um ponto inválido.

A posição de cada ponto e seus respectivos seguimentos encontrados (Figura 3), são correspondentes na Imagem

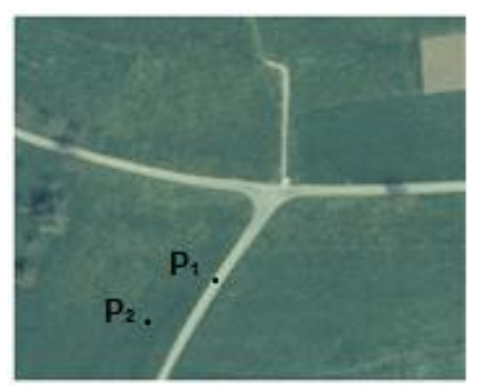

Base (Figura 2), onde a posição de um ponto na Imagem Original possui a mesma posição na Imagem Base como demonstra a Figura 8.

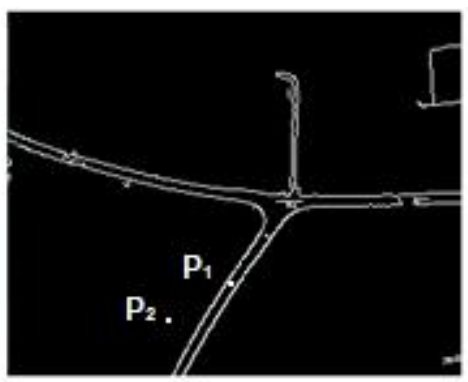

Figura 8. Posição de pontos na Imagem Original em relação à Imagem Base.

Algoritmo de B-Spline (etapa 6.1): O francês Pierre Bézier na década de 60 definiu uma forma de modelar uma curva que descrevia uma variedade muito grande de curvas matemáticas, que facilitaria o processo de desenhar o contorno de carros. Esta curva ficou famosa e é muito utilizada até hoje, é chamada Curva de Bézier. Uma curva é apresentada por conjunto de pontos cujas coordenadas satisfazem uma expressão polinomial as quais podem ser construídas parametricamente com coeficientes que são coordenadas de pontos de controle (PALUSZNY; BOEHM;
PRAUTZSCH, 2002). São definidas as funções:

$$
N_{i, j}(t)=\frac{t-t_{i}}{t_{i+j}-t_{i}} N_{i, j-1}(t)+\frac{t_{i+j+1}-t}{t_{i+j+1}-t_{i+1}} N_{i+1 . j-1(t)}
$$

Assim, a curva é definida, como:

$$
C(t)=\sum_{i=0}^{n} P_{i} N_{i . p(t)}
$$

Na Figura 9, os pontos P1, P2, P3 e P4 determinam as características da curva, como concavidade, curvatura ao longo do segmento e suavidade. 


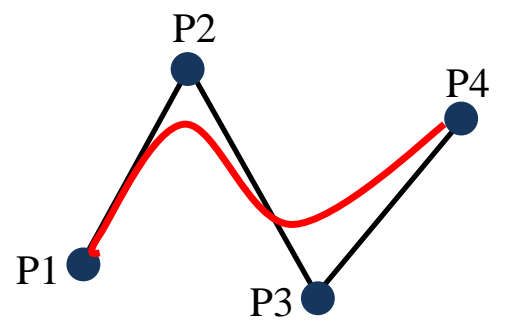

Figura 9. Exemplo de curva de Bézier.

Segundo Farin (1992), B-Splines são junções de várias curvas de Bézier que possibilitam implementar um controle local da curva, ou seja, alterar a posição de um ponto de controle não reflete em toda a curva, somente na região vizinha ao ponto. Essa região vizinha pode conter problemas em alguns casos, quando há a proximidade dos pixels. Este foi um problema constante que ocorreu neste trabalho, em virtude dos muitos pontos próximos que foram gerados na etapa 3, como mostra a Figura 3. A Figura 10 ilustra um exemplo da aplicação da curva B-Spline.

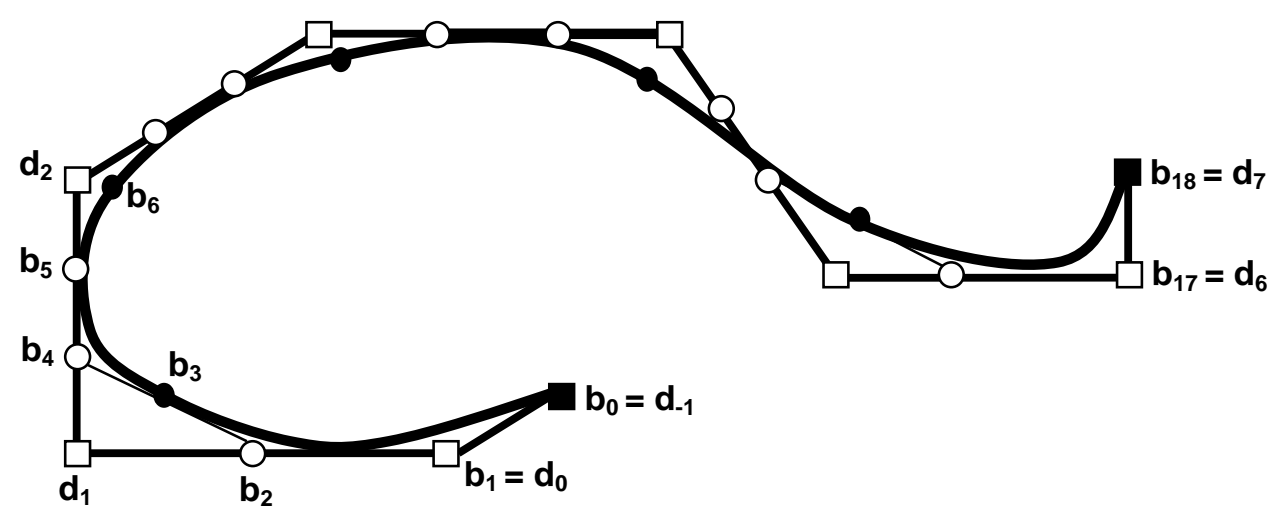

Figura 10. Exemplo de curva B-Spline.

Fonte: (FARIN, 1992).

\section{Algoritmo de Douglas-Peucker}

(etapa 6.2): Douglas e Peucker (1973) criaram um algoritmo para generalização de linha e de forma independente a qual consiste em, simplificar linhas poligonais. Para isso, é definida uma tolerância $t$, de forma que traçada uma reta entre dois pontos extremos do polígono, os pontos intermediários a uma distancia $x<t$ são eliminados.

O algoritmo de Douglas-Peucker é mais utilizado para simplificação de linhas poligonais, o critério de eliminação dos pontos analisa a distância de cada um, a uma reta que une o primeiro e o último ponto da linha. Se todos os pontos estão a uma distância menor que uma tolerância 
conhecida, a linha será representada apenas pelo primeiro e pelo último ponto. Se algum ponto está a uma distância maior, o ponto mais distante da reta é considerado o último e o algoritmo reinicia calculando as distâncias. A Figura 11 ilustra a aplicação do algoritmo de Douglas-Peucker.
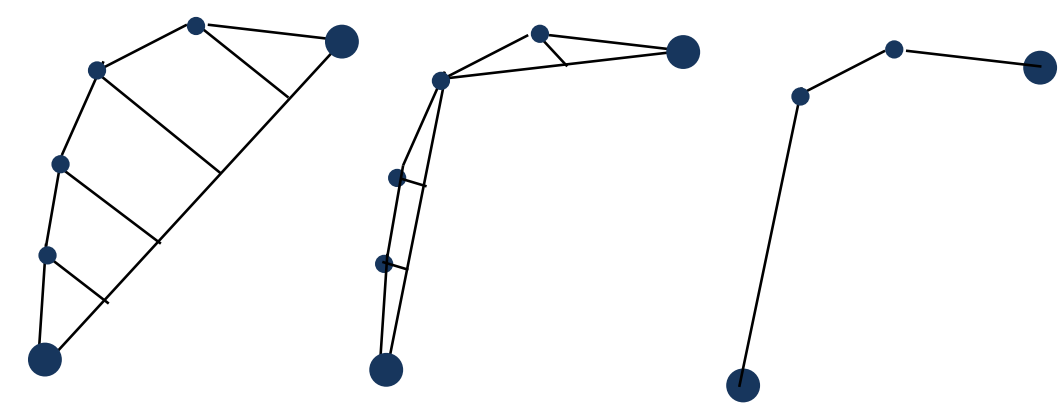

Figura 11. Representação da Aplicação de Douglas-Peucker.

Construção das Sementes de Rodovias

(etapa 7): A construção das semente de rodovias é obtida através do conhecimento das bordas para cada ponto de um segmento.

A detecção das bordas é realizada através da simplificação do fator de inclinação visto na etapa 5. Na Figura 12, percorrendo do ponto $\mathrm{P}_{1}$ aos pontos $\mathrm{P}_{1}^{\prime}$ e $\mathrm{P}_{1}^{\prime \prime}$, encontra-se pixels brancos (Bordas), que são armazenados em um vetor.

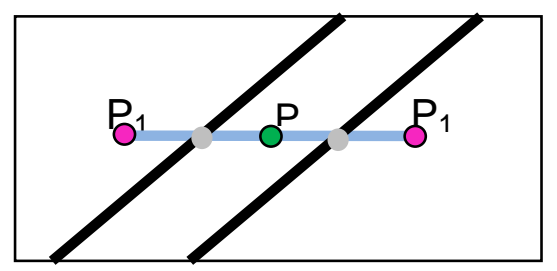

Figura 12. Detecção de bordas.

As bordas encontradas para cada gerando as sementes de rodovias. A Figura 13 segmento são ligadas através de retas mostra a construção destas sementes. 


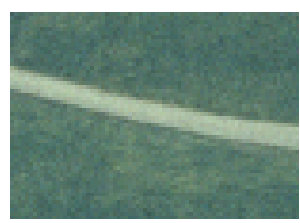

(a)

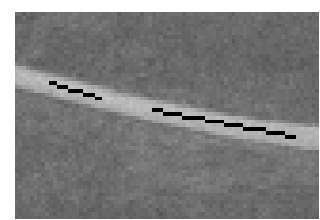

(b)

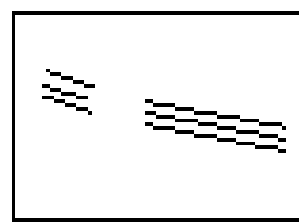

(c)

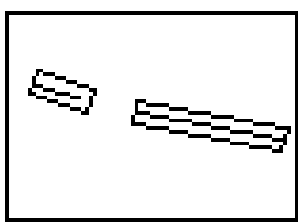

(d)

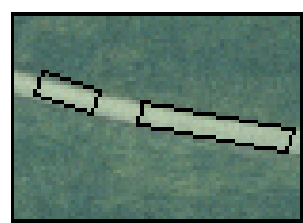

(e)

Figura 13. (a) Imagem de Entrada, (b) segmentos de rodovias, (c) reconhecimento das bordas, (d) ligação para formação das sementes, e (e) bordas sobrepostas na Imagem de Entrada.

\section{EXPERIMENTOS}

Os experimentos foram realizados com duas imagens aéreas com resolução de 1143 x 655 pixels. Essas imagens utilizadas são de alta resolução e apresentam níveis de dificuldades diferenciadas.
A imagem de Experimento 1 (Figura 14) contêm rodovias com largura aproximada de sete pixels. Nesta imagem estão presentes também estradas rurais e edificações. Uma pequena porção de solo exposto e um cruzamento do tipo "T", também podem ser observados.

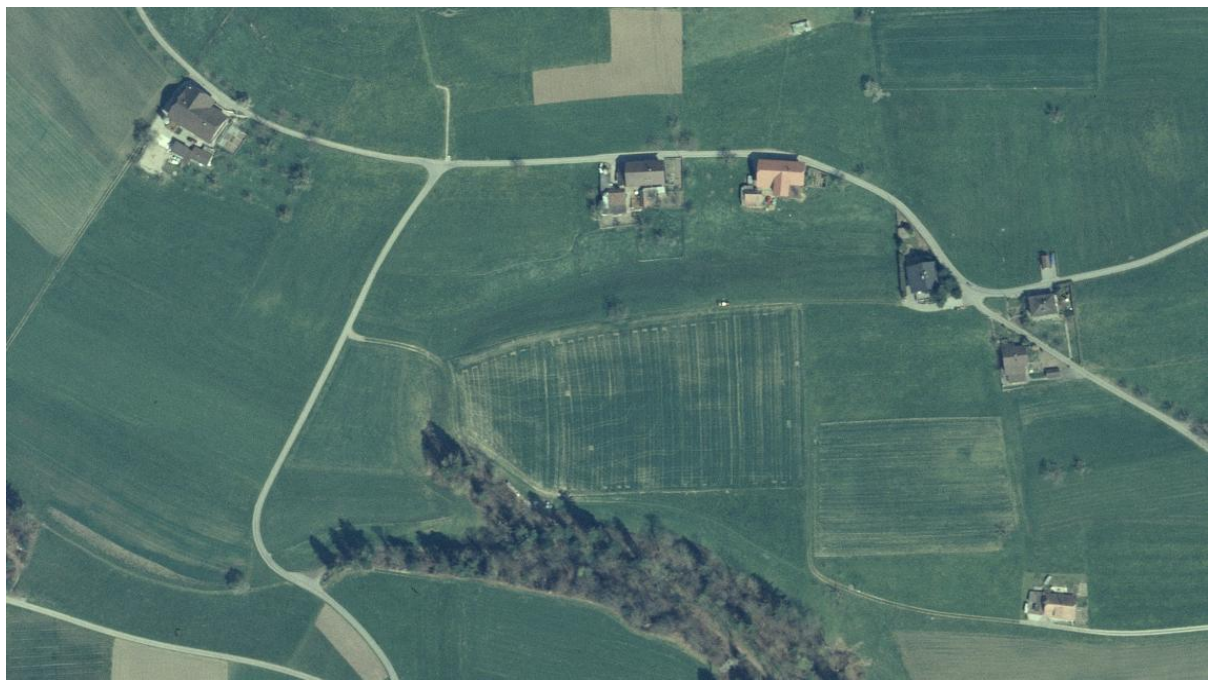

Figura 14. Imagem usada no Experimento 1.

A imagem de Experimento 2 (Figura

15) contêm rodovias com largura aproximada de seis pixels. Nesta imagem, também estão presentes estradas rurais e edificações. 


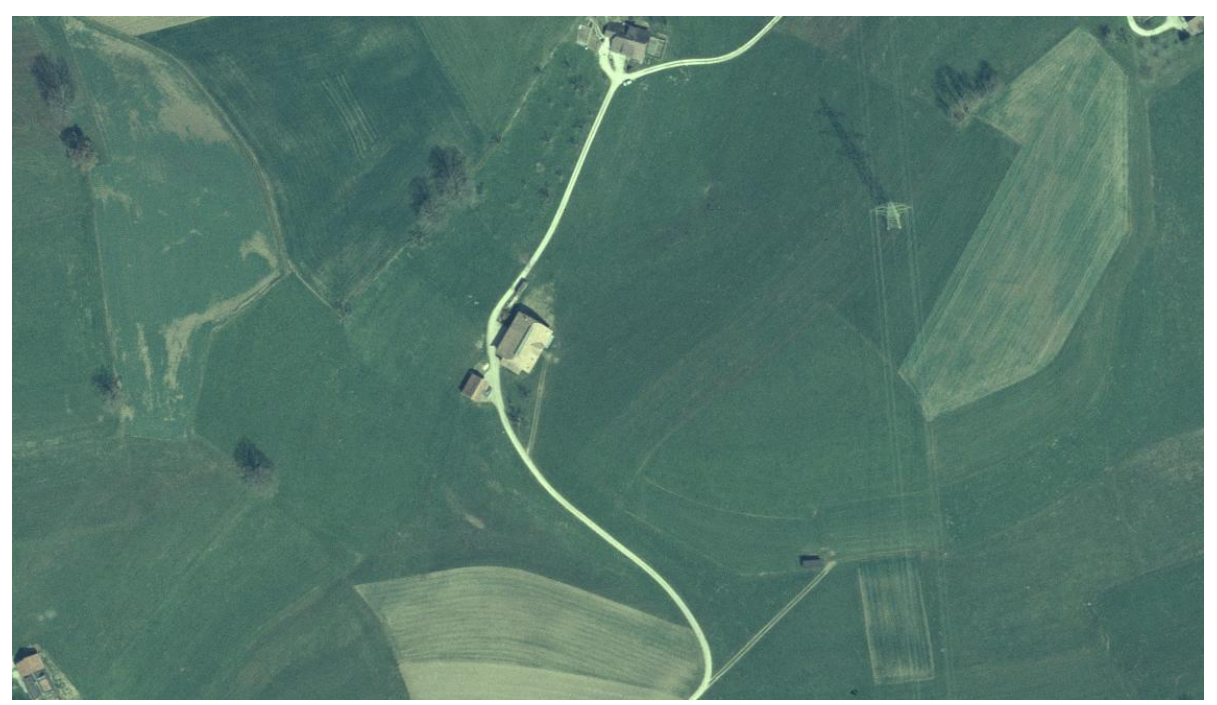

Figura 15. Imagem usada no Experimento 2.

\subsection{Experimento 1}

Primeiramente, nesse experimento é executada a etapa 1 que visa a redução da imagem, neste caso a subamostragem, o que faz eliminar informações irrelevantes e indesejáveis. A etapa 2 visa a criação da
Imagem Base a partir da Imagem Original. Essa Imagem Base é o resultado da aplicação do algoritmo de Canny. A Figura 16 mostra em (a) a Imagem usada nesse Experimento (Imagem Original), e em (b) a Imagem Base (após aplicação do Canny).

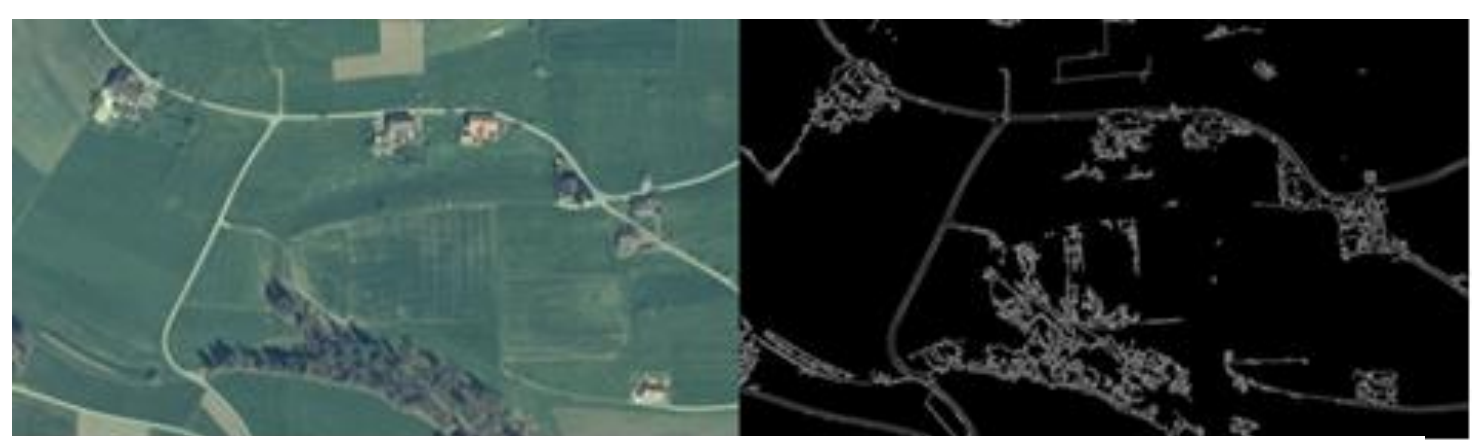

(a)

(b)

Figura 16. (a) Imagem de Entrada, (b) Imagem Base após aplicação da detecção de Bordas (Canny).

A Figura 17 ilustra o resultado gerado pelo contíguas aproximadamente paralelas. A imagem detector de linhas do Canny Modificado, onde se mostra também vários pontos que não fazem parte pode notar que as rodovias principais foram da rodovia.

detectadas como linhas e não como duas bordas 


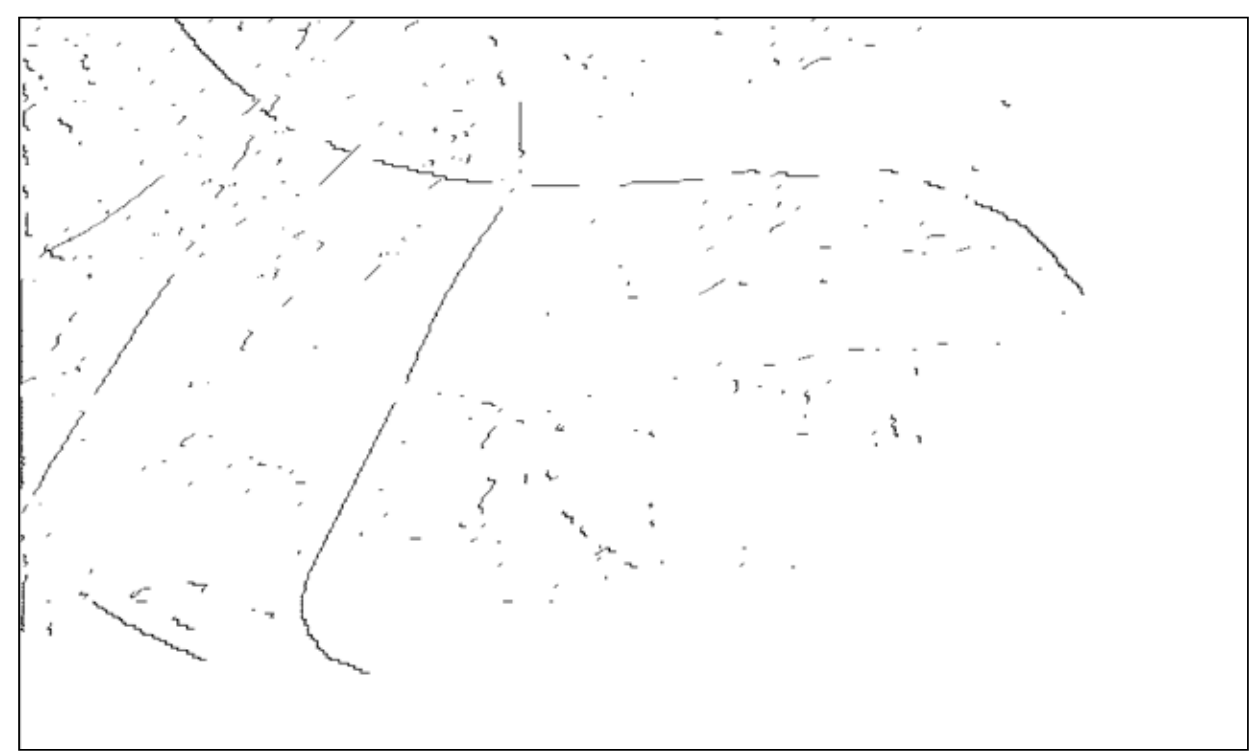

Figura 17. Aplicação Canny Modificado na Imagem Original do Experimento 1.

A eliminação dos pontos inválidos é comparação entre elas, observa-se que obteve a aplicada (etapa 5), e demonstrada na Figura 18. eliminação de pontos que não são considerados Analisando a Figura 17 e Figura 18, e fazendo uma pertencentes às rodovias.

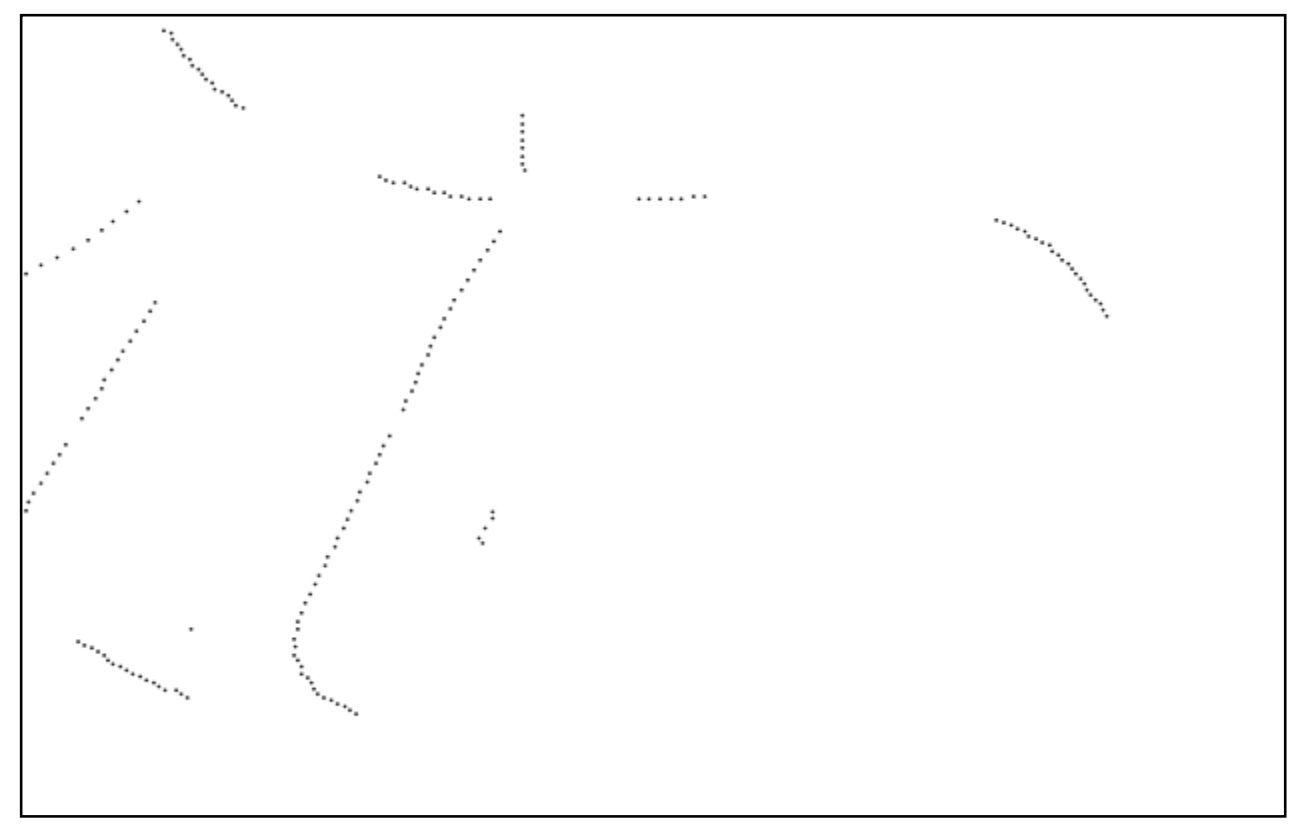

Figura 18. Eliminação dos pontos inválidos.

Com os pontos que formam a Figura 19 mostra a aplicação desse algoritmo possíveis sementes de rodovia, foi aplicado o sobre os possíveis pontos válidos. algoritmo de Douglas-Peucker (etapa 6.2). A 


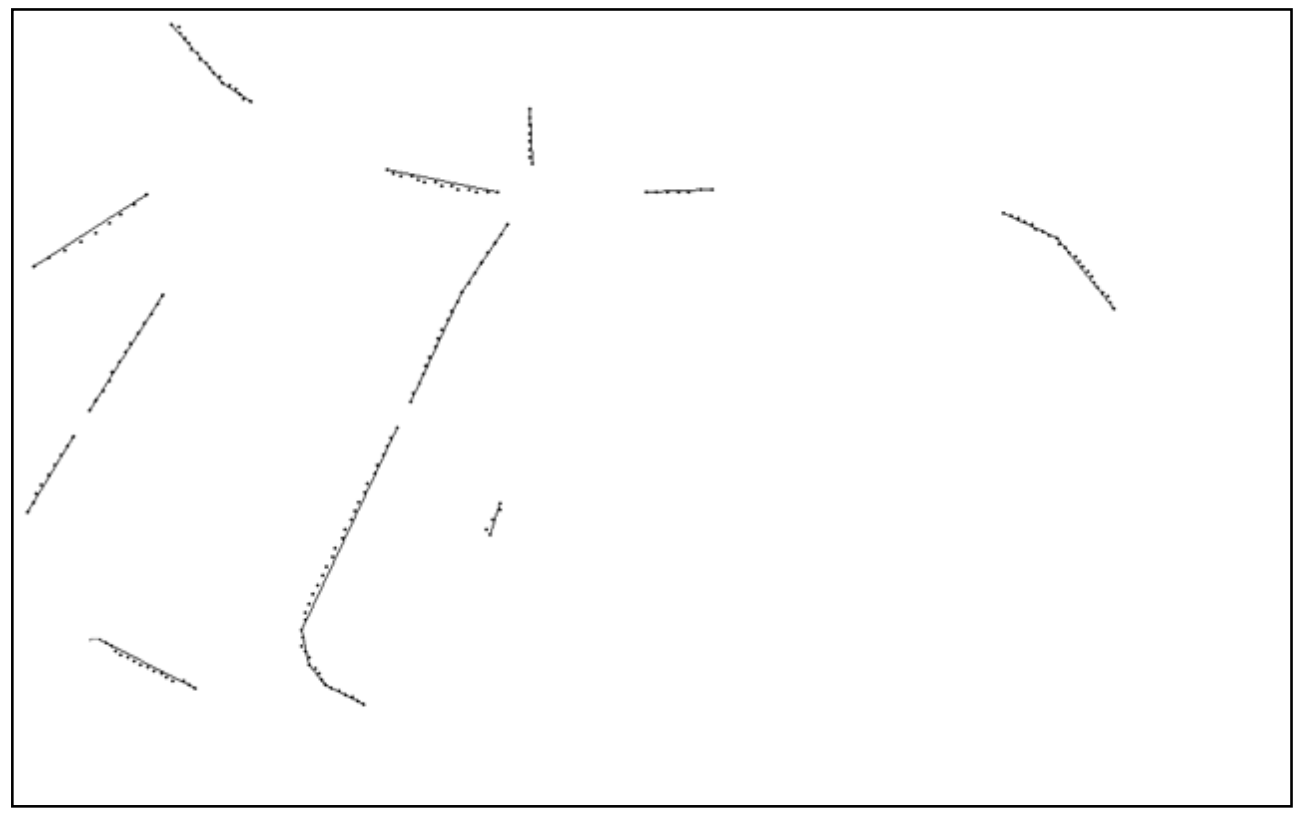

Figura 19. Aplicação do algoritmo de Douglas-Peucker.

Com os seguimentos formados, são construídas as sementes de rodovia a partir do conhecimento das bordas na imagem. A
Figura 20 mostra a ligação dos pontos encontrados e formação das sementes de rodovias (etapa 7).

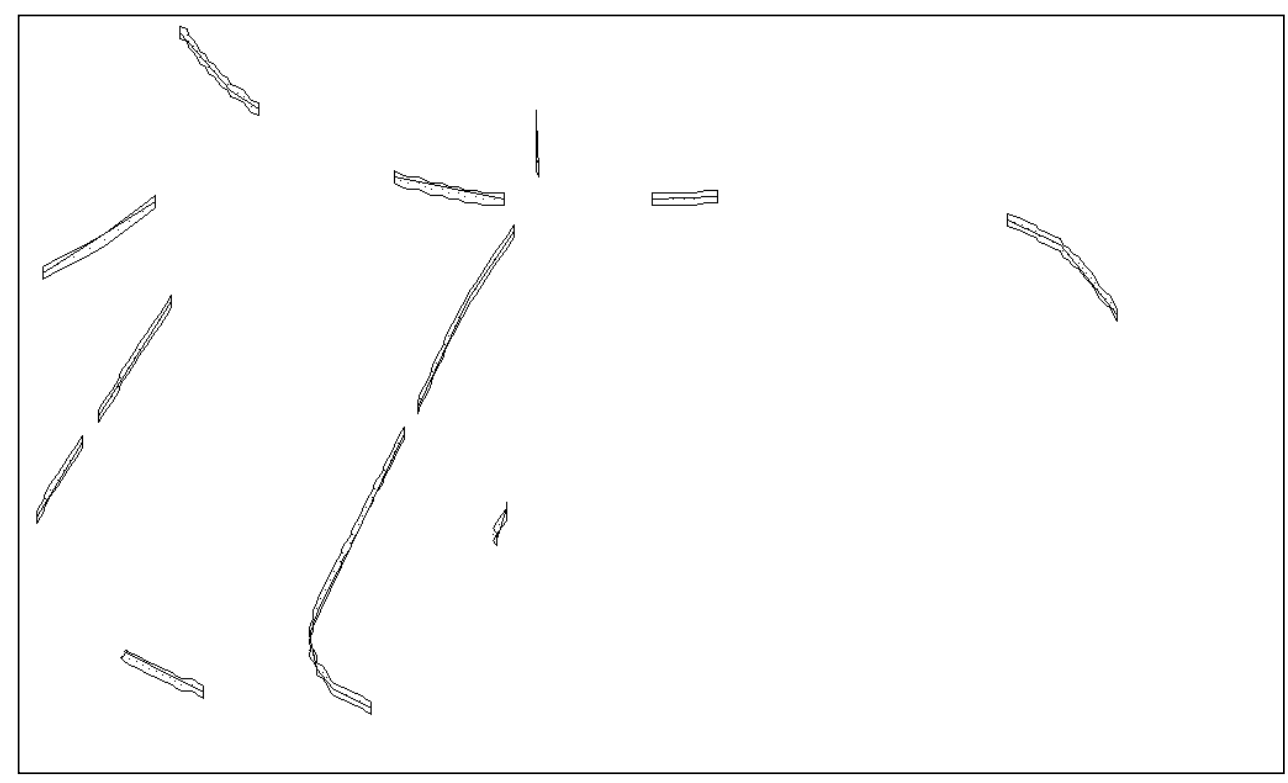

Figura 20. Formação das sementes de rodovia. 
Por fim, as sementes encontradas são mostrado na Figura 21.

projetadas na Imagem de Entrada conforme

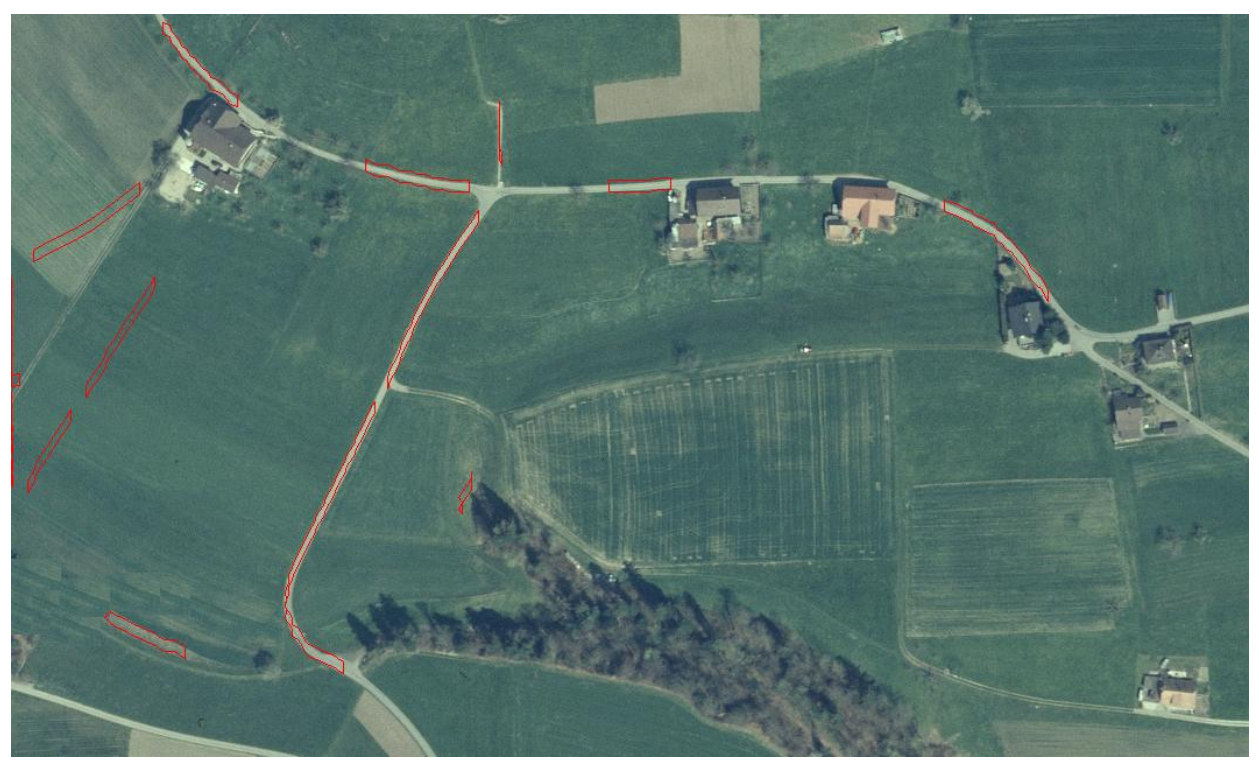

Figura 21. Sementes de rodovia projetadas na Imagem Original.

\subsection{Experimento 2}

Nesse experimento, são executadas as mesma etapas do Experimento 1. A Figura 22 mostra em (a) a Imagem Original usada nesse experimento, e em (b) a Imagem Base (após aplicação do Canny).

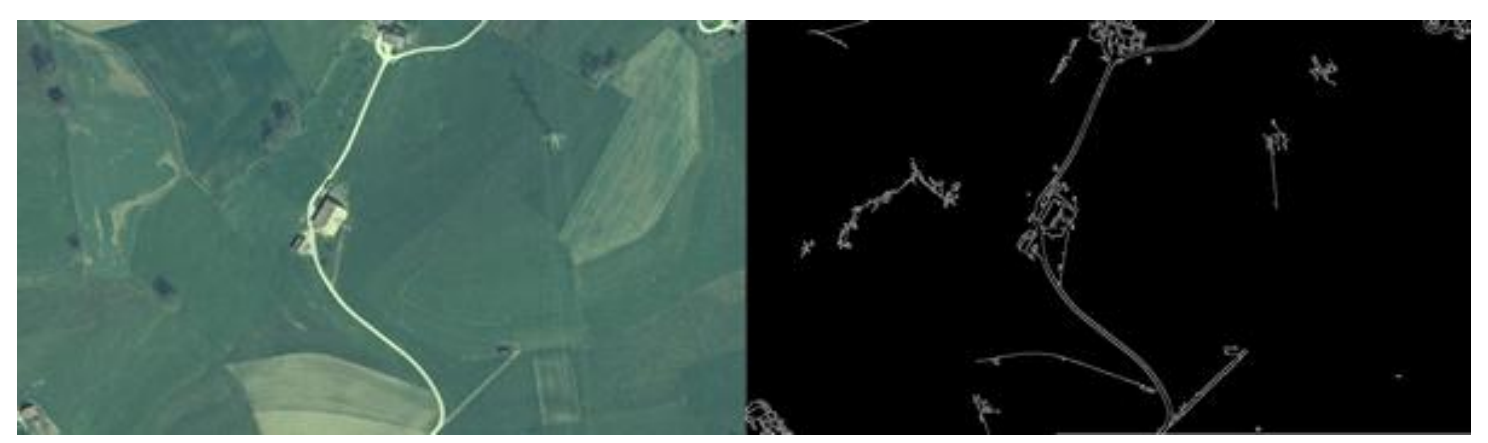

(a)

(b)

Figura 22. (a) Imagem de Entrada e (b) Imagem Base após a aplicação da detecção de Bordas (Canny).

A Figura 23 ilustra o resultado gerado pelo detector de linhas Canny Modificado. Assim como ocorreu no Experimento 1, a imagem também mostra vários pontos que não fazem parte da rodovia. 


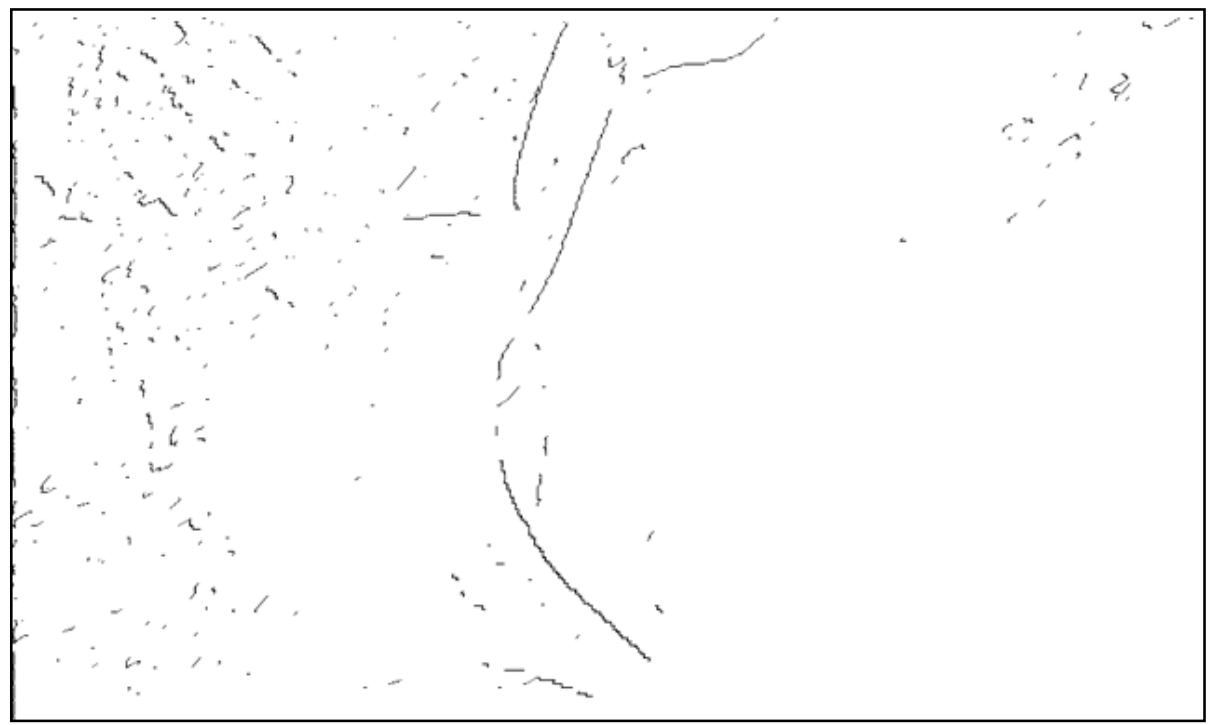

Figura 23. Aplicação do Canny Modificado na Imagem Original do Experimento 2.

A eliminação dos pontos inválidos é ilustrada na Figura 24, e apresentou o mesmo comportamento do Experimento 1, onde obteve-se a eliminação de vários pontos que não pertencem às rodovias.

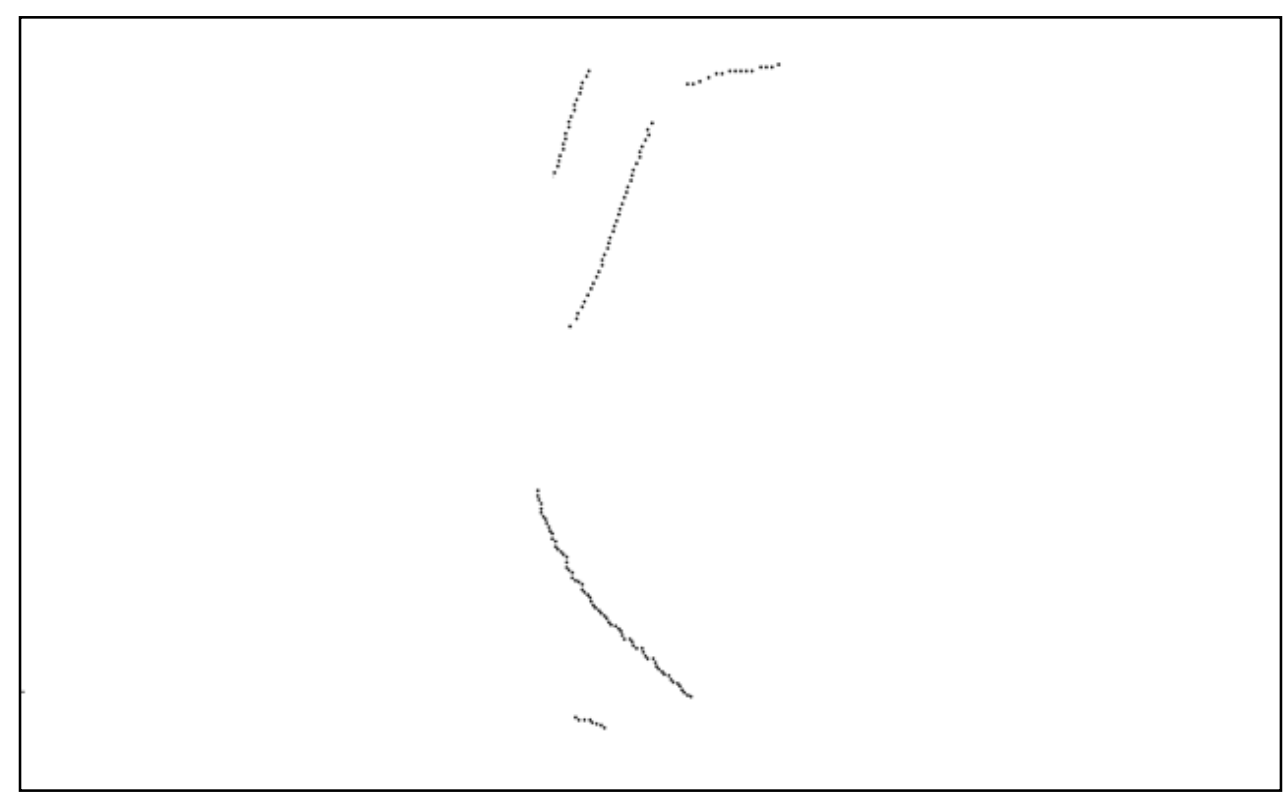

Figura 24. Eliminação dos pontos inválidos não pertencentes às rodovias.

Após a aplicação do algoritmo de Douglas-Peucker, obteve-se o resultado mostrado na Figura 25. 


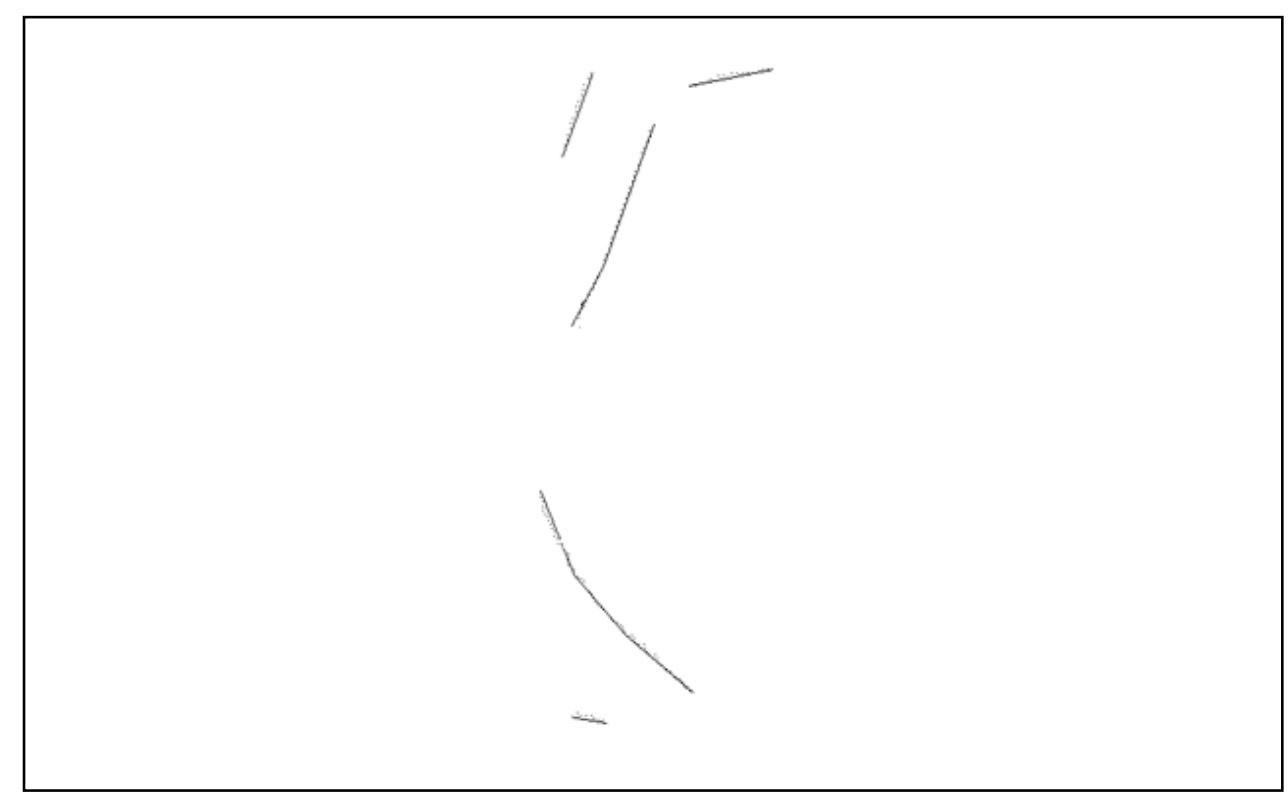

Figura 25. Aplicação do algoritmo de Douglas-Peucker.

Com os seguimentos formados, são construídas as sementes de rodovia a partir do conhecimento das bordas na imagem. A
Figura 26 mostra a ligação dos pontos encontrados formando as sementes de rodovias.

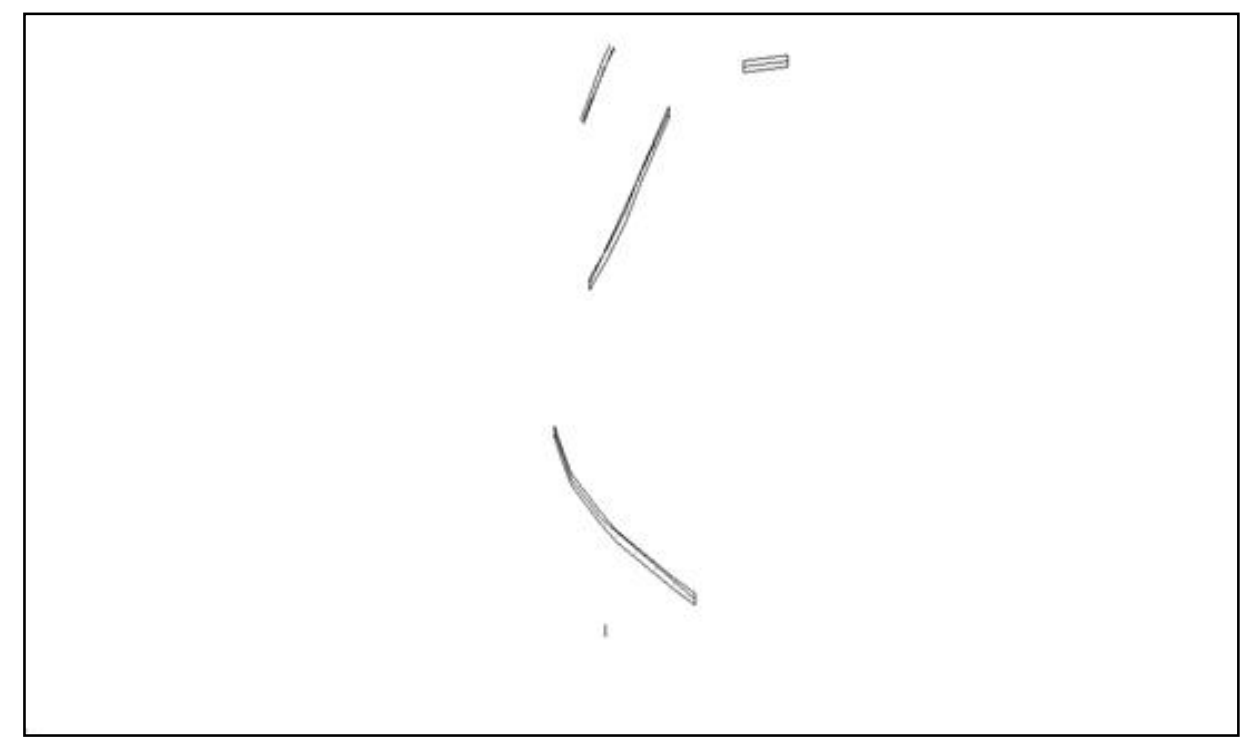

Figura 26. Formação das sementes de rodovias.

Por fim, as sementes encontradas são projetadas na Imagem Original conforme ilustrado na Figura 27. 


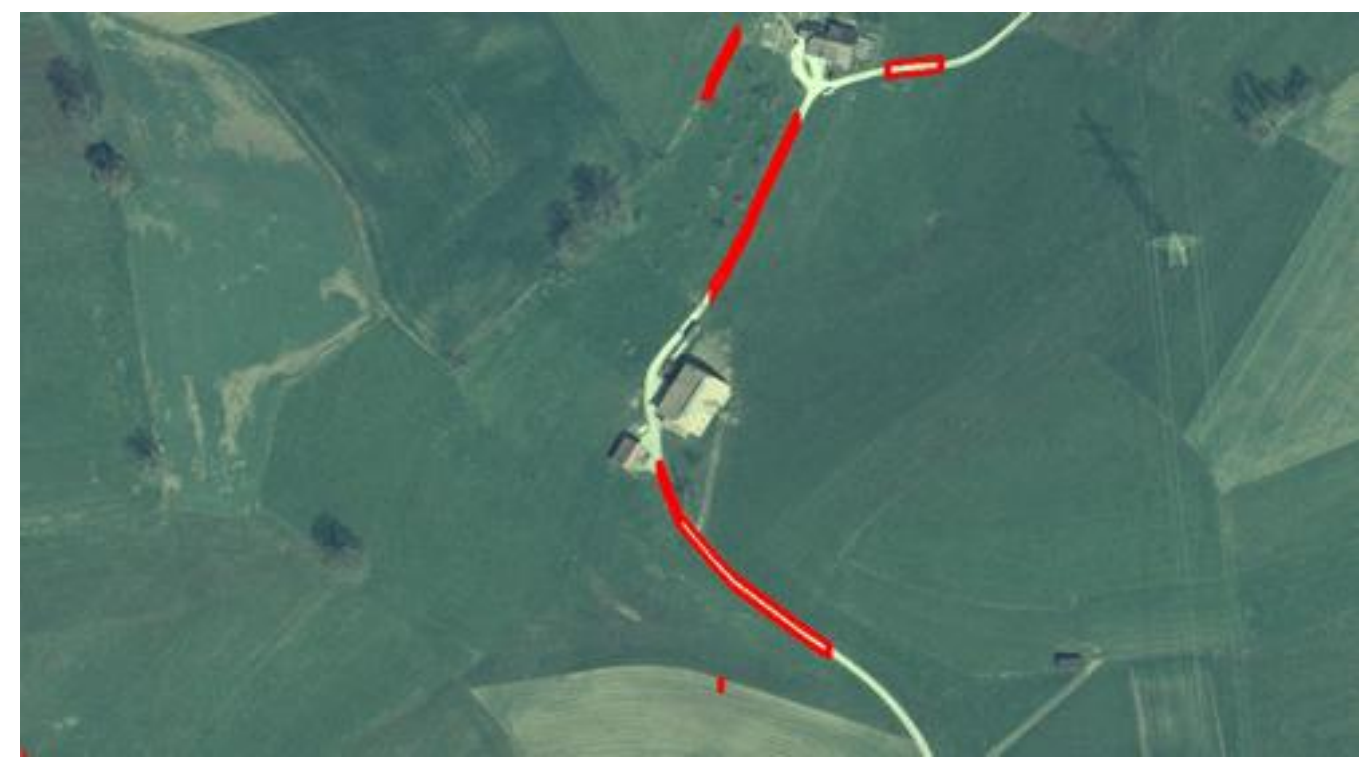

Figura 27. Sementes de rodovia projetadas na Imagem Original.

\section{CONCLUSÃO E TRABALHOS FUTUROS}

Dois experimentos foram realizados, as imagens além de conter o objeto de interesse, possuem detalhes que são complexos de serem analisadas, como, estradas rurais, edificações e sombras.

A metodologia de extração de rodovias demonstrado neste trabalho foi bastante satisfatória. O algoritmo foi capaz de analisar os pontos válidos e fazer o reconhecimento das sementes. Em relação à primeira etapa da metodologia, destaca-se o fato de que o método Canny Modificado, desenvolvido por Dal Poz e Silva (2002) foi de extrema importância no reconhecimento das linhas em relação às bordas.

As principais constatações e conclusões de cada análise nas imagens são:

A imagem de Teste 1 contém cenas complexas de serem analisadas, a aplicação do Canny Modificado obteve conhecimento de vários pontos inválidos, que mesmo aplicando a correção destes pontos, se obteve algumas sementes que não fazer parte da rodovia devido a imagem ser de grande dificuldade de análise.

A imagem de Teste 2 contém cenas de complexidade média, a aplicação do Canny Modificado obteve conhecimento de vários pontos inválidos, que aplicando a correção destes pontos, se obteve uma imagem satisfatória, mesmo ter encontrado um segmento em uma estrada rural.

Um trabalho futuro de grande valia, seria a ligação das sementes encontradas, tornando assim os seguimentos mais contundentes, aumentando a proporção de tamanho dos segmentos. Outro trabalho para desenvolvimento futuro, de grande interesse, seria a extração de cruzamentos de rodovias. 


\section{REFERÊNCIAS}

ALVES, F. L. B. Avaliação da extração semiautomática de rodovias sobre uma imagem híbrida para atualização cartográfica. 2007. Dissertação (Mestrado) Instituto Militar de Engenharia, Rio de Janeiro.

BAJCSY, R.; TAVAKOLI, M. Computer recognition of roads from satellite pictures. IEEE Transactions on Systems, Man, and Cybernetics, v. 6, n. 9, p. 76-84, 1976. http://dx.doi.org/10.1109/TSMC.1976.4309568

BRASIL. Lei no 9.503, de 23 de setembro de 1997. Diário Oficial da República Federativa do Brasil, Brasília, DF, v. 189, n. 06, p. 38, 24 set. 1997.

CANNY, J. A. Computational approach to edge detection. IEEE Transactions on Pattern Analysis and Machine Intelligence, Washington, DC, USA, v. 8, n. 6, pp. 679-698, 1986.

http://dx.doi.org/10.1109/TPAMI.1986.4767851

COELHO, L.; BRITO, J. N. Fotogrametria digital. Rio de Janeiro: EdUERJ, 2007.

DAL POZ, A. P.; AGOURIS, P. Um algoritmo de otimização global para a extração de rodovias em imagens digitais. Revista Brasileira de Cartografia, Curitiba, n. 53, p. 65-72, 2001.

DAL POZ, A. P.; SILVA, M. A. O. Active testing and edge analysis for road centreline extraction. In: ISPRS COMISSION III SYMPOSION 'PHOTOGRAMMETRIC COMPUTER VISION, 2002, Graz, Austria. The International Archives of the Photogrammetry, Remote Sensing and Spatial Information Sciences, v. 34. p. 44-47, 2002.

DAL POZ, A. P.; VALE, G. M. Dynamic programming approach for semi-automated road extraction from medium and high resolution images. In: PHOTOGRAMMETRY IMAGE ANALYSIS. Munich. The International
Archives of the Photogrammetry, Remote Sensing and Spatial Information Science, v. 34, p. 87-91, 2004.

DOUGLAS, D.; PEUCKER, T. Algorithms for the reduction of the number of points required to represent a digitized line or its caricature. The Canadian Cartographer, v. 10, n. 2, p. 112122, dec. 1973.

FARIN, G. Curves and surfaces for computer aided geometric design - a practical guide. 3 ed. [s.I.]: Academic Press, 1992.

FISCHLER, M. A.; TENENBAUM, J. M.; WOLF, $H$. C. Detection of roads and linear structures in low-resolution aerial imagery using a multisource knowledge integration technique.

Computer Graphics and Image Processing, San Francisco, v.15, p.201-223, 1981. http://dx.doi.org/10.1016/0146-664X(81)900563

GENDLER, R. Capitulo 10: a imagem híbrida. Uma filosofia astro de imagem-novo. Em Ratledge, David Astrofotografia Digital: O Estado da Arte. Springer. 2005. p. 135-149.

ISHIBASHI, R. Extração de segmentos de rodovia em imagens de resoluções variadas usando o princípio de bordas paralelas. 2008. Dissertação (Mestrado em Ciências Cartográficas) - Universidade Estadual Paulista.

ISHIBASHI, R.; DAL POZ, A.P. Extração automática de segmentos lineares de rodovias em imagens de resolução variadas. Boletim de Ciências Geodésicas, sec. Artigos, Curitiba, v. 15, n. 3, p.352-372, jul-set, 2009.

PALUSZNY, M.; BOEHM, W.; PRAUTZSCH, $\mathrm{H}$. Bézier- and B-spline techniques. March, 2002. Disponível em: http://wtsim.googlecode.com/hghistory/c651377e3bb9a0da099e63043cdfa1f9 d6140736/docs/Buchauswahl.pdf. 
PONZONI, F. J.; NOVO, E. Introdução ao sensoriamento remoto. São José dos Campos: INPE, 2001.

SANTOS, D. J. Extração semiautomatica do cruzamento de vias de áreas urbanas com uso de ortoimagens de alta resolução espacial. 2010. Dissertação (Mestrado em Ciências Geodésicas) - Setor de Ciências da Terra, Departamento de Geomática, Universidade Federal do Paraná, Curitiba.

ZANIN, R. B.; ISHIBASHI, R.; DAL POZ, A. P. Detector de linha de Steger: potencial na extração de rodovia. In: Simpósio Brasileiro de Geomática, 2. Colóquio Brasileiro de Ciências Geodésicas, 5. Anais... Presidente Prudente, SP: FCT/UNESP, p. 1-11, 2007. 